\title{
Comparing the Effect of Reciproc, ProTaper Next and R-Endo in the Removal of Gutta-percha/Sealer and GuttaFlow during Retreatment
}

\author{
Kaveh Nasiri ${ }^{*}$ and Karl-Thomas Wrbas ${ }^{2}$ \\ ${ }^{1} D D S$, MSc, Department of Endodontics, Center for Operative Dentistry and Periodontology, University of \\ Dental Medicine and Oral Health, Danube Private University, Krems, Austria \\ ${ }^{2}$ Professor, Department of Operative Dentistry and Periodontology, Center for Dental Medicine, Oral and \\ Maxillofacial Surgery, Medical Center, University of Freiburg, Freiburg i.Br., Germany; Department of \\ Endodontics, Center for Operative Dentistry and Periodontology, University of Dental Medicine and Oral \\ Health, Danube Private University, Krems, Austria
}

* Corresponding author: Kaveh Nasiri, DDS, MSc (Endodontics), Department of Endodontics, Center for Operative Dentistry and Periodontology, University of Dental Medicine and Oral Health, Danube Private University, Krems, Austria, E-mail: DDS.Nasiri@web.de

\begin{abstract}
Aim: To evaluate the efficacy of three rotary instrumentation systems in removing gutta-percha/sealer and GuttaFlow from root canals and to determine retreatment time.

Methodology: Sixty palatal roots of extracted first maxillary molars were selected. The samples were prepared with ProTaper Universal and then randomly divided into two groups $(n=30)$. In groups A and $B$, the root canals were filled employing lateral compaction of GP/AH Plus and GuttaFlow2, respectively. The samples in each group were randomly divided into three subgroups $(n=10)$. Groups $A 1$ and B1 were retreated using Reciproc. ProTaper Next was used in groups A2 and B2, whereas groups A3 and B3 were retreated with R-Endo system. Retreatment time was recorded. The roots were split longitudinally and examined under a stereomicroscope and then photographed. The remaining filling material was calculated using Image $\mathrm{J}$ software. A two-way analysis of variance (ANOVA) was conducted to examine the effect of three systems in the removal of filling material. Moreover, a Tukey HSD test was used to perform multiple comparisons $(\alpha=0.05)$.
\end{abstract}

Results: Removal of GuttaFlow from the canals was easier and faster than that of GPIAH Plus $(p<0.05)$. Generally, the results revealed that compared to other systems, $\mathrm{R}$-Endo in group A left less filling material inside the canals $(p<0.05)$. It also required less time to reach working length than the other systems $(p<0.05)$. One PTN instrument and two Reciproc instruments were fractured during the retreatment procedures.
Conclusions: Based on the findings of this study, none of the systems could completely remove the root filling material from the root canals. However, R-Endo was found to be the most effective instrument in the removal of GP/AH Plus.

\section{Keywords}

GuttaFlow, ProTaper Next, Reciproc, R-Endo

\section{Abbreviations}

PTN: ProTaper Next; Rec: Reciproc; PTU: ProTaper Universal; GP: Gutta-percha

\section{Introduction}

The main goal of non-surgical root canal retreatment is the retention of teeth, in order to restore periapical tissue's health and improve patient's quality of life and chewing ability. In this regard, contemporary endodontic techniques in non-surgical root canal retreatment are shown to have satisfactory outcome [1]. The prerequisite for non-surgical root canal retreatment is adequate removal of filling material from root canals in order to enhance cleaning, shaping and filling of the root canals [2]. In a systematic review by Torabinejad, et al. [3] it was reported that orthograde retreatment has a higher success rate $(83.0 \%)$ than endodontic surgery $(71.8 \%)$ at 4 to 6 years.

Citation: Nasiri K, Wrbas KT (2019) Comparing the Effect of Reciproc, ProTaper Next and R-Endo in the Removal of Gutta-percha/Sealer and GuttaFlow during Retreatment. Int J Oral Dent Health 5:087. doi.org/10.23937/2469-5734/1510087

Accepted: April 29, 2019: Published: May 01, 2019

Copyright: (c) 2019 Nasiri K, et al. This is an open-access article distributed under the terms of the Creative Commons Attribution License, which permits unrestricted use, distribution, and reproduction in any medium, provided the original author and source are credited. 
Gutta-percha is the most universally used filling material for the obturation of root canals. It should be removed when secondary therapy is indicated [4]. So far, a number of techniques such as hand instrument, rotary $\mathrm{Ni}$-Ti systems, ultrasonic and laser with or without the use of solvents have been proposed for the removal of root filling material during retreatment procedures $[2,5,6]$. Previous studies have reported that the removal of filling material was not complete in any of the root canals $[2,4]$. The apical third is the most probable area to be cleaned and disinfected in the course of successful retreatment as that is the third, where microorganisms generally persist $[2,4]$. It is worth mentioning that the combined use of different techniques has shown to be more effective than only using one technique for the removal of filling material [4].

Different Ni-Ti systems have been suggested for removing filling material from root canals [7-9]. Retreatment files are specifically designed for the use in retreatment procedures such as R-Endo system. R-Endo system consists of four rotary files and one hand file (Re 25/0.12, R1 25/0.08, R2 25/0.06, R3 25/0.04 and $\mathrm{Rm}$ 25/0.04). The cross-section of R-Endo instruments has three equally spaced cutting edges with neither radial lands nor an active tip [7]. Furthermore, Reciproc and ProTaper Next systems were used for the initial root canal therapy, however they can also be used in retreatment procedures [8,9]. Reciproc system has three different sizes: R25 25/0.08, R40 40/0.06 and R50 $50 / 0.05$. It has an s-shaped cross-sectional design and a non-cutting tip [8]. As for ProTaper Next, it consists of five Ni-Ti rotary instruments: X1 17/0.04, X2 25/0.06, X3 30/0.07, X4 40/0.06 and X5 50/0.06. PTN files produce an asymmetrical rotation and have a unique rectangular cross-sectional design [9].

Based on literature, comparing different root filling materials during retreatment is one of the most highly researched topics and therefore, it is worth investigating [10]. Thus, in line with literature, this study aimed to evaluate the efficacy of Reciproc, ProTaper Next and R-Endo in the removal of gutta-percha/sealer and GuttaFlow from root canals. Another objective of this study was to determine the time for retreatment. The null hypothesis tested, was that there would be no differences between removal of gutta-percha/sealer and GuttaFlow during retreatment procedures.

\section{Materials and Methods}

Sixty extracted first maxillary molars with single palatal roots and fully formed apices were used in this experimental study. Palatal roots were verified with radiography as having single canals of $\leq 30^{\circ}$ curvatures in buccopalatal direction. The canal curvatures were determined employing the Schneider method [11]. Their range was between $0^{\circ}$ and $30^{\circ}$ with a mean of $14.05^{\circ}$ $\pm 8.37^{\circ}$ which indicates that the palatal roots had mild $\left(<10^{\circ}\right)$, moderate $\left(10-25^{\circ}\right)$ or severe $\left(>25^{\circ}\right)$ degrees of canal curvatures. The classification of canal curvatures in the present study followed that of the study by Alfouzan and Jamleh [12]. Residues of soft and hard tissues were removed mechanically. The selected samples were immersed in Sodium Chloride $0.9 \%$ for 48 hours and then rinsed with distilled water. After access cavity preparation, working length was measured using a size 10 C-Pilot $^{\circledR}$ (VDW, Munich, Germany). In fact, the file was placed into the canal until it was visible at the apical foramen. Also, the working length was established 1 $\mathrm{mm}$ shorter of this length.

Regarding the instrumentation of root canals, ProTaper Universal system (Dentsply Sirona, Ballaigues, Switzerland) was used according to the manufacturer instruction with a sequence of SX, S1, S2, F1 and F2 (size 25/0.08 taper). After each instrument, root canals were rinsed with two $\mathrm{ml}$ of $2.5 \% \mathrm{NaOCl}$. The smear layer was removed with four $\mathrm{ml}$ of $17 \%$ EDTA within one minute, followed by four $\mathrm{ml}$ of distilled water. Subsequently, the canals were dried with paper points and randomly divided into two groups of $A$ and $B(n=30)$.

Next stage was filling the samples. Samples of group A were filled using lateral compaction technique. Gutta-percha master cones ISO 25 were coated with sealer AH Plus (Dentsply DeTrey, Konstanz, Germany) and inserted into the palatal root canals. Also, a finger spreader was inserted for laterally pack and subsequently, accessory cones were inserted into the canals until they were completely filled. Samples of group B were filled with GuttaFlow2 (Coltene/Whaledent, Langenau, Germany). The convenient syringe delivery system, ROEKO GuttaFlow2 was coated with master cones ISO 25 and slowly inserted into the palatal roots. Subsequently, employing a backfill technique, GuttaFlow was used to fill any additional space that may exist in the canals.

Regardless of root length, the root filling material was homogeneously extended to $12 \mathrm{~mm}$ from the apex to the coronal third allowing the use of heatened hand plugger. In addition, the volume of filling material was approximately the same for all palatal roots. Furthermore, access cavities were sealed with temporary filling such as Coltosol F (Coltene/Whaledent, Langenau, Germany). Finally, the teeth were radiographed in buccopalatal direction to determine the quality of the filling procedure. The samples were then stored for two months at $37{ }^{\circ} \mathrm{C}$ in $100 \%$ humidity to ensure complete setting of the filling material.

The samples in each group were randomly divided into three subgroups $(n=10)$ and an ANOVA test was performed to assure that there were no significant differences with regard to the degrees of canal curvatures within the six groups $(p=0.361)$. Afterwards, the palatal roots were dyed and numbered with three different colors of nail polish (A1: Green, A2: Red, A3: Black; B1: Green, B2: Red and B3: Black). 


\section{Removal of filling material}

Groups A1 and B1: In these groups, retreatment procedures were carried out using Reciproc (VDW, Munich, Germany) system. According to the manufacturer's instructions, R25 (size 25/0.08) instrument was used in an up and down motion until reaching working length. Final apical enlargement was performed with R40 (size 40/0.06). Groups A2 and B2: In these groups, filling material was removed using ProTaper Next system (Dentsply Sirona, Ballaigues, Switzerland). X3 (size 30/0.07) and $X 2$ (size 25/0.06) files were used in a crown-down technique. $X 3$ was used for the removal of filling material in the cervical and middle thirds and $X 2$ was used in the apical third. Final apical enlargement was performed with X4 (size 40/0.06).

Groups A3 and B3: In these groups, R1, R2 and R3 files of R-Endo (Micro-Mega, Besancon, France) were sequentially employed. As for the removal of filling material in different areas, R1 files (size 25/0.08) were used in the cervical, R2 (size 25/0.06) and R3 (size $25 / 0.04$ ) were used in the middle and apical thirds respectively. Final apical enlargement was performed with Revo-S Classic (Micro-Mega, Besancon, France) AS 40/0.06.

A stopwatch was used to measure the retreatment time for each specimen in the three stages: When the working length was reached, when the filling material was completely removed and when the whole process was complete (total time). Retreatment procedures were carried out with an $\mathrm{x}$-smart plus endo-motor
(Dentsply Sirona, Ballaigues, Switzerlnad) in all groups. Speed and torque were set for each instrument according to the manufacturer's instructions. All groups had the same irrigation protocol for retreatment. After each instrument, canals were irrigated with $2 \mathrm{ml}$ of $2.5 \% \mathrm{NaO}$ $\mathrm{Cl}$ followed by a final rinse with $4 \mathrm{ml}$ of distilled water. Each instrument was discarded after being used in two root canals. The palatal roots were decoronated with a diamond disc up to $12 \mathrm{~mm}$ of the reference surface.

Furthermore, the roots were split longitudinally with a diamond disc and both root halves were photographed under a stereomicroscope with $20 \mathrm{X}$ magnification (Bresser, Rhede, Germany). The images were then imported in Image J software (National Institutes of Health (NIH), Bethesda, MD, USA). The root canals were divided into three parts of four $\mathrm{mm}$ and the residual filling material in the canal was demarcated. The regions and residual filling material were calculated in $\mathrm{mm}^{2}$. Afterwards, the percentages of residual filling material in the coronal, middle and apical thirds were measured using the following equation: Filling mateial $(\%)=\frac{\text { area of residual filling material }}{\text { area of canal wall }} \times 100$

Figure 1 shows an example of the evaluation of residual material via Image $\mathrm{J}$.

\section{Statistical analysis}

Statistical analysis was performed with SAS software program (SAS institute Inc., Cary, NC, USA). A two-way analysis of variance (ANOVA) was conducted to analyze

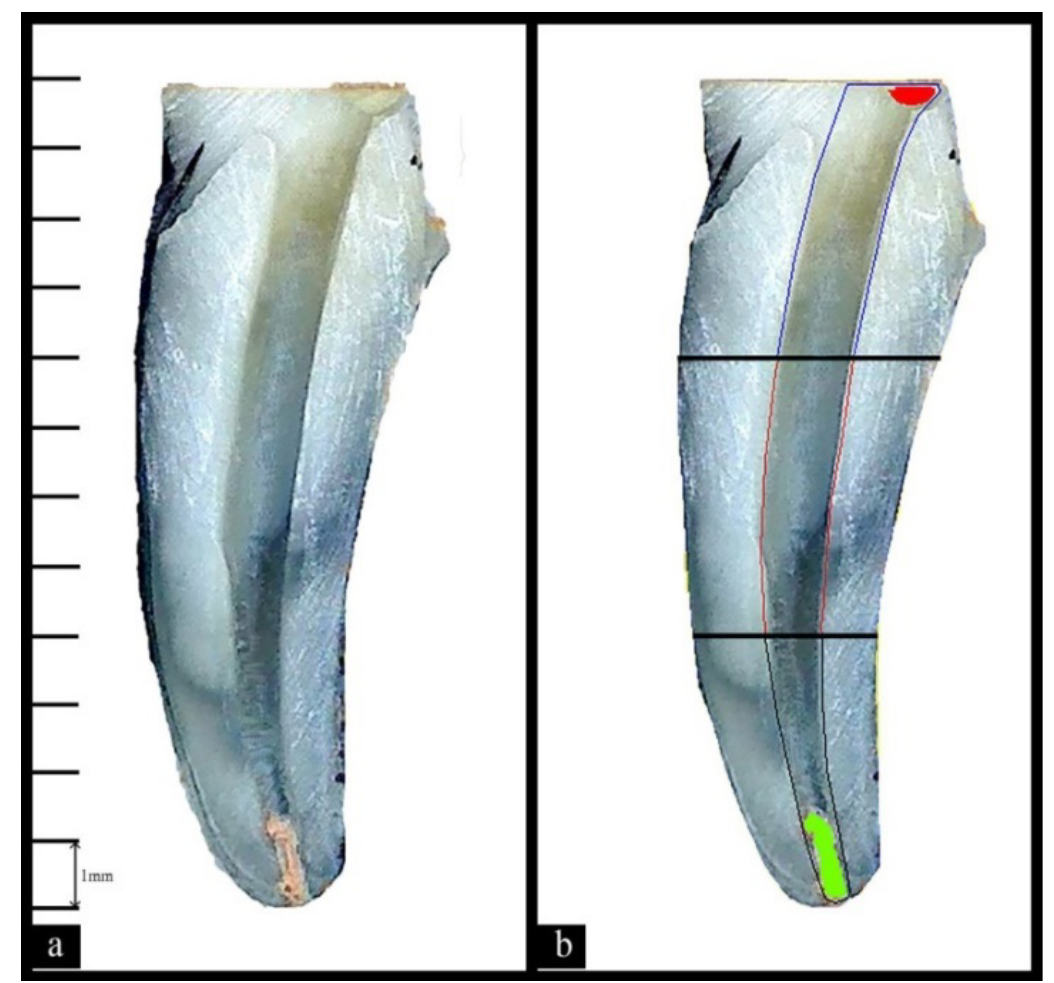

Figure 1: Remaining filling material evaluation with Image $\mathrm{J}$ software in the canal in the coronal, middle and apical thirds. a) Before analysis; b) After analysis with Image $\mathrm{J}$ software. 
Table 1: Shows the mean and standard deviation of each group for remnants of gutta-percha/sealer and GuttaFlow across all systems and regions, as well as the total results.

\begin{tabular}{|c|c|c|c|c|}
\hline Region & System & \multicolumn{3}{|l|}{ Groups } \\
\hline & & \multicolumn{3}{|l|}{ Mean \pm SD } \\
\hline & & $\mathbf{A}^{*}$ & $\mathbf{B}^{*}$ & Mean $\left(\mathbf{A}^{*}, \mathbf{B}^{*}\right)$ \\
\hline \multirow[t]{4}{*}{ Coronal } & Reciproc & $22.91^{\mathrm{ABa}} \pm 11.34$ & $11.7^{\mathrm{Ab}} \pm 11.54$ & $17.31^{\mathrm{A}} \pm 12.53$ \\
\hline & PTN & $25.3^{\mathrm{Aa}} \pm 14.22$ & $11.42^{\mathrm{Ab}} \pm 12.49$ & $18.36^{A} \pm 14.84$ \\
\hline & R-Endo & $15.28^{\mathrm{Ba}} \pm 14.07$ & $12.06^{\mathrm{Aa}} \pm 13.09$ & $13.67^{\mathrm{A}} \pm 13.34$ \\
\hline & Mean (Rec, PTN, R-Endo) & $21.16^{a} \pm 13.46$ & $11.73^{b} \pm 11.96$ & \\
\hline \multirow[t]{4}{*}{ Middle } & Reciproc & $14.71^{\mathrm{Aa}} \pm 12.35$ & $14.17^{\mathrm{Aa}} \pm 16.1$ & $14.44^{\mathrm{A}} \pm 13.97$ \\
\hline & PTN & $20.91^{\mathrm{Aa}} \pm 13.81$ & $11.5^{\mathrm{Aa}} \pm 12.2$ & $16.2^{\mathrm{A}} \pm 13.57$ \\
\hline & R-Endo & $11.09^{\mathrm{Aa}} \pm 7.28$ & $10.05^{\mathrm{Aa}} \pm 12.05$ & $10.57^{A} \pm 9.73$ \\
\hline & Mean (Rec, PTN, R-Endo) & $15.57^{\mathrm{a}} \pm 11.97$ & $11.9^{a} \pm 13.16$ & \\
\hline \multirow[t]{4}{*}{ Apical } & Reciproc & $25.57^{A a} \pm 13.06$ & $14.73^{\mathrm{Ab}} \pm 13.47$ & $20.15^{A} \pm 14.3$ \\
\hline & PTN & $25.58^{\mathrm{Aa}} \pm 11.48$ & $9.79^{\mathrm{Ab}} \pm 10.07$ & $17.69^{\mathrm{AB}} \pm 13.27$ \\
\hline & R-Endo & $13.34^{\mathrm{Ba}} \pm 9.36$ & $12.14^{\mathrm{Aa}} \pm 9.86$ & $12.74^{\mathrm{B}} \pm 9.38$ \\
\hline & Mean (Rec, PTN, R-Endo) & $21.5^{\mathrm{a}} \pm 12.54$ & $12.22^{b} \pm 11.05$ & \\
\hline \multirow[t]{4}{*}{ Total } & Reciproc & $63.19^{A a} \pm 16.65$ & $40.6^{\mathrm{Ab}} \pm 11.24$ & $51.89^{A} \pm 18.04$ \\
\hline & PTN & $71.79^{\mathrm{Aa}} \pm 17.18$ & $32.71^{\mathrm{Ab}} \pm 21.21$ & $52.25^{A} \pm 26.65$ \\
\hline & R-Endo & $39.71^{\mathrm{Ba}} \pm 12.96$ & $34.25^{\mathrm{Aa}} \pm 15.39$ & $36.98^{\mathrm{B}} \pm 14.13$ \\
\hline & Mean (Rec, PTN, R-Endo) & $58.23^{a} \pm 19.77$ & $35.85^{b} \pm 16.26$ & \\
\hline
\end{tabular}

Means with the same letter are not significantly different from each other; lowercase letters indicate significant differences between groups $(P<0.05)$; uppercase letters indicate significant differences among systems $(P<0.05) A^{*}=$ Gutta-percha/Sealer; $B^{*}=$ GuttaFlow.

the residual filling material among the regions (coronal, middle and apical), systems (Rec, PTN and R-Endo) and between the groups ( $A$ and $B$ ). Moreover, a Tukey HSD test was applied for pair-wise comparisons (95\% confidence intervals). Finally, the retreatment time was analyzed using the above mentioned tests.

\section{Results}

Remnants of filling material were observed in all hemisection samples (Table 1 ).

Regarding the coronal third region, the results in group $A$ revealed that $\mathrm{R}$-Endo system left the least residuals of filling material, while PTN system left the highest and this result was statistically significant $(p<$ 0.05). However, no statistically significant difference was observed among the three systems in group B. As for the middle third, there was no statistically significant difference in the residuals of filling material among the three systems and between the two groups ( $p>0.05$ ). The results in the apical third of group A showed that R-Endo system left significantly less remnants of filling material than Reciproc and PTN systems ( $p<0.05)$. However, no statistically significant difference was observed among the three systems in group $B(p>0.05)$. In total, according to the results, the type of system in group A had a significant main effect on the amount of residuals of root filling material. R-Endo system left the least residuals while Reciproc and PTN systems showed significantly higher residuals of filling material $(p<0.05)$. The specimens in group $B$, on the other hand, demon- strated no statistically significant difference among the three systems ( $p>0.05$ ). Furthermore, GuttaFlow was removed significantly easier than gutta-percha/sealer from the root canals.

Results of the retreatment times were observed in table 2. The results for the first retreatment time in group A revealed that compared to Reciproc and PTN systems, R-Endo system was significantly faster with regard to working length ( $p<0.05)$. In group $B$, however, Reciproc system required less time than the other two systems ( $p>0.05$ ). As for T2 in group A, Reciproc system was found to be significantly slower than PTN and R-Endo systems with regard to the complete removal of filling material $(p<0.05)$. The mean of the two groups confirmed this result. Regarding $\mathrm{T} 2$ in group $\mathrm{B}$, the results showed that the complete removal of the filling material took approximately the same amount of time in all three systems and therefore, no significant difference was found ( $p>0.05$ ). The results for T3 in group A indicated that PTN and R-Endo systems were significantly faster than Reciproc ( $p<0.05)$. In group $B$, however, no significant difference was observed regarding the total time among the three systems. In sum, it can be reported that GuttaFlow was removed significantly faster than gutta-percha/sealer from the root canals.

\section{Fractured Instruments}

Two Reciproc ( $R$ 25) instruments with canal curvatures of $29^{\circ}, 26^{\circ}$ and one PTN (X4) instrument with $30^{\circ}$ were fractured during retreatment procedures. The 
Table 2: Provides mean and standard deviation for the retreatment time (T1, T2 and T3) across all systems and groups.

\begin{tabular}{|c|c|c|c|c|}
\hline \multirow[t]{3}{*}{ Time } & \multirow[t]{3}{*}{ System } & \multicolumn{3}{|l|}{ Groups } \\
\hline & & \multicolumn{3}{|l|}{ Mean \pm SD } \\
\hline & & $A^{*}$ & $\mathrm{~B}^{*}$ & Mean $\left(A^{*}, B^{*}\right)$ \\
\hline \multirow[t]{4}{*}{$\mathrm{T1}$} & Reciproc & $87.9^{\mathrm{Aa}} \pm 25.46$ & $26.82^{\mathrm{Ab}} \pm 7.55$ & $57.36^{\mathrm{AB}} \pm 36.27$ \\
\hline & PTN & $87.61^{\mathrm{Aa}} \pm 34.75$ & $35.54^{\mathrm{Ab}} \pm 7.46$ & $61.58^{A} \pm 36.22$ \\
\hline & R-Endo & $51.4^{\mathrm{Ba}} \pm 9.48$ & $39.24^{\mathrm{Aa}} \pm 12.76$ & $45.32^{\mathrm{B}} \pm 12.59$ \\
\hline & Mean (Rec, PTN, R-Endo) & $75.63^{a} \pm 30.13$ & $33.87^{b} \pm 10.66$ & \\
\hline \multirow[t]{4}{*}{ T2 } & Reciproc & $205.95^{\mathrm{Aa}} \pm 81.95$ & $52.29^{A b} \pm 21.71$ & $129.12^{\mathrm{A}} \pm 98.72$ \\
\hline & PTN & $91.67^{\mathrm{Ba}} \pm 37.84$ & $58.5^{\mathrm{Aa}} \pm 25.77$ & $75.09^{\mathrm{B}} \pm 35.81$ \\
\hline & R-Endo & $91.81^{\mathrm{Ba}} \pm 37.38$ & $56.96^{\mathrm{Aa}} \pm 17.5$ & $74.38^{\mathrm{B}} \pm 33.57$ \\
\hline & Mean (Rec, PTN, R-Endo) & $129.81^{\mathrm{a}} \pm 77.21$ & $55.92^{b} \pm 23.2$ & \\
\hline \multirow[t]{4}{*}{$\mathrm{T} 3$ (T1+T2) } & Reciproc & $293.85^{\text {Aa }} \pm 91.69$ & $79.1^{\mathrm{Ab}} \pm 26.26$ & $186.47^{A} \pm 128.23$ \\
\hline & PTN & $179.28^{\mathrm{Ba}} \pm 45.02$ & $94.05^{\mathrm{Ab}} \pm 27.56$ & $136.66^{\mathrm{B}} \pm 56.86$ \\
\hline & R-Endo & $143.21^{\mathrm{Ba}} \pm 43.61$ & $96.2^{\mathrm{Aa}} \pm 16.89$ & $119.7^{B} \pm 40.22$ \\
\hline & Mean (Rec, PTN, R-Endo) & $205.44^{a} \pm 89.98$ & $89.87^{b} \pm 24.46$ & \\
\hline
\end{tabular}

Means with the same letter are not significantly different from each other; lowercase letters indicate significant differences between groups $(P<0.05)$; uppercase letters indicate significant differences among systems $(P<0.05) A^{*}=$ Gutta-percha/Sealer; $B^{*}=$ GuttaFlow; T1 = time to reach WL; T2 = time for complete removal of filling material.

broken instruments were successfully removed and the time needed for their removal was not recorded.

\section{Discussion}

The most important stage in the orthograde secondary root canal therapy is the removal of filling material, including an effective debridement and use of irrigation solution on microorganisms that trigger post treatment diseases [13]. The present study examined the effect of Reciproc, ProTaper Next and R-Endo systems in the removal of filling material. In addition, this study aimed to measure and record the retreatment time. In this study, the samples were prepared with ProTaper Universal. PTU is a well-known system for preparation which is made of conventional $\mathrm{Ni}-\mathrm{Ti}$ alloy and is defined as an active cutting with a convex triangular cross-section for $\mathrm{F} 2$ [14]. One of the distinguishing features of the present study is the use of two obturation techniques.

In this study, three different $\mathrm{Ni}-\mathrm{Ti}$ systems were used for retreatment procedures. Reciproc movement reduces the stress on the instrument allowing the use of counter clockwise and clockwise movements. Reciproc and PTN are produced with M-Wire alloy. M-Wire has higher resistance to cyclic fatigue and therefore, has better flexibility than traditional nickel-titanium $[9,15]$. However, in the present study three $\mathrm{Ni}-\mathrm{Ti}$ instruments were fractured. Those were tooth number 6 and 10 in Reciproc system and number 46 in PTN system with canal curvatures of $29^{\circ}, 26^{\circ}$ and $30^{\circ}$ respectively. This may be due to the fact that the instruments were used twice or the fact that the three teeth had severe canal curvatures. This result was suggested by previous studies $[2,12]$.

As concluded in previous studies, when the enlargement in retreatment procedures is greater than the initial preparation, the amount of residual filling material in the canal decreases $[16,17]$. A study conducted by Mohammadzadeh Akhlaghi, et al. [18] showed that preparation with larger size/taper instruments is more effective for cleaning and disinfecting the apical third. Therefore, in the present study, the cross sectional diameters of the final instruments were chosen with larger size. The final preparation was performed with files size 40 to refine the root canal preparation, especially in the apical third. The taper of file size 40 was increased from DO (diameter) to D1 by $0.06 \mathrm{~mm}$ in width and length. The findings of the current study revealed that the ideal file size after retreatment is ISO 40/0.06 taper in straight, mild and moderate canal curvatures.

Retreatment time was recorded in three categories of T1 (to reach WL), T2 (complete removal of filling material) and T3 (total time) as done by Iriboz and Sazak Ovecoglu [10]. Based on the results of this study, all types of rotary $\mathrm{Ni}-\mathrm{Ti}$ systems in group $\mathrm{B}$ required less time in order to remove GuttaFlow compared to the time needed for the removal of the gutta-percha/ sealer in group A. This result is consistent with that of Khedmat, et al. study [19].

So far, various methodologies have been used in order to determine residuals of filling material such as rendering transparency [7], $x$-ray imaging [9], micro-CT [17], cone beam CT [19] and splitting roots longitudinally [20]. Vertical splitting is a well-established and an adequate method, which was employed in this study [21,22]. In this study, the specimens were split vertically and images of the halves were obtained using a stereomicroscope and then evaluated with Image J software. Image J software is a well-known program for analysis of scientific images [23]. 
According to the data of the results in the present study, GuttaFlow was removed significantly easier from the root canals in group $B$ in comparison to the removal of gutta-percha/sealer in group $A$. Thus, the null hypothesis tested was rejected. This finding is in line with that of the study conducted by Khedmat, et al. [19]. Furthermore, in group A, more residuals of root filling were observed in the coronal third than in the middle third. As Capar, et al. [16] reported this result might be rooted in the fact that Gates Gliden drills were not used in the coronal third.

Generally, it can be reported that R-Endo system removed gutta-percha and sealer significantly better than other systems which is consistent with the result of Mollo, et al. study [2]. This finding can be attributed to the use of R-Endo retreatment system followed by Revo-S as final preparation. Moreover, the findings of this study showed that none of the Ni-Ti rotary systems completely removed all root filling material from the root canals, which is in agreement with previous studies [13,24].

\section{Conclusions}

Based on the findings of the present investigation, it can be concluded that R-Endo and Revo-S system in group $A$, were found to be effective in the removal of GP/AH Plus from the root canals. Moreover, R-Endo reached working length faster than Reciproc and PTN systems in group A. Finally, GuttaFlow was removed significantly easier than GP/AH Plus from the root canals.

\section{References}

1. He J, White RK, White CA, Schweitzer JL, Woodmansey KF (2017) Clinical and patient-centered outcomes of nonsurgical root canal retreatment in first molars using contemporary techniques. J Endod 43: 231-237.

2. Mollo A, Botti G, Prinicipi Goldoni N, Randellini E, Paragliola $\mathrm{R}$, et al. (2012) Efficacy of two Ni-Ti systems and hand files for removing gutta-percha from root canals. Int endod J 45: 1-6.

3. Torabinejad M, Corr R, Handysides R, Shabahang S (2009) Outcomes of nonsurgical retreatment and endodontic surgery: A systematic review. J Endod 35: 930-937.

4. Preetam CS, Chandrashekhar M, Gunaranjan T, Kumar SK, Miskeen Sahib SA, et al. (2016) A comparative evaluation of two rotary $\mathrm{Ni}-\mathrm{Ti}$ instruments in the removal of gutta-percha during retreatment. J Int Soc Prev Community Dent 6: S131-S136.

5. Kasam S, Mariswamy AB (2016) Efficacy of different methods for removing root canal filling material in retreatment-an in-vitro study. J Clin Diagn Res 10: 06-10.

6. Keles A, Arslan H, Kamalak A, Akcay M, Sousa-Neto MD, et al. (2015) Removal of filling materials from ovalshaped canals using laser irradiation: A micro-computed tomographic study. J Endod 41: 219-224.

7. Tasdemir T, Er K, Yildirim T, Celik D (2008) Efficacy of three rotary $\mathrm{NiTi}$ instruments in removing gutta-percha from root canals. Int Endod J 41: 191-196.

8. Nevares G, de Albuquerque DS, Freire LG, Romeiro K, Fogel HM, et al. (2016) Efficacy of ProTaper next compared with reciproc in removing obturation material from severely curved root canals: A micro-computed tomography study. J Endod 42: 803-808.
9. Ozyurek T, Ozsezer-Demiryurek E (2017) Efficacy of ProTaper next and ProTaper Universal retreatment systems in removing gutta-percha in curved root canals during root canal retreatment. J Istanb Univ Fac Dent 51: 7-13.

10. Iriboz E, Sazak Ovecoglu H (2014) Comparison of ProTaper and Mtwo retreatment systems in the removal of resinbased root canal obturation materials during retreatment. Aust Endod J 40: 6-11

11. Schneider SW (1971) A comparison of canal preparations in straight and curved root canals. Oral Surg Oral med Oral pathol 32: 271-275.

12. Alfouzan K, Jamleh A (2018) Fracture of nickel titanium rotary instrument during root canal treatment and re-treatment: $A$ 5-year retrospective study. Int Endod J 51: 157-163.

13. Alberto Rubino G, de Miranda Candeiro GT, Gonzales Freire L, Faga Iglecias E, de Mello Lemos E, et al. (2018) Micro-CT evaluation of gutta-percha removal by two retreatment systems. Iran Endod J 13: 221-227.

14. Ha JH, Kwak SW, Kim SK, Kim HC (2016) Screw-in forces during instrumentation by various file systems. Restor Dent Endod 41: 304-309.

15. Bartols A, Robra BP, Walther W (2017) The ability of Reciproc instruments to reach full working length without glide path preparation: A clinical retrospective study. Peer J 5.

16. Capar ID, Arslan H, Ertas H, Gok T, Saygili G (2015) Effectiveness of ProTaper Universal retreatment instruments used with rotary or reciprocating adaptive motion in the removal of root canal filling material. Int Endod J 48: 79-83.

17. Silva E, Belladonna FG, Carapia MF, Muniz BL, Rocha MS, et al. (2018) Micro-computed tomographic evaluation of canal retreatments performed by undergraduate students using different techniques. Restor Dent Endod 43: e5.

18. Mohammadzadeh Akhlaghi N, Rahimifard N, Moshari A, Vatanpour M, Darmiani S (2014) The effect of size and taper of apical preparation in reducing intra-canal bacteria: A quantitative sem study. Iran Endod J 9: 61-65.

19. Khedmat S, Azari A, Shamshiri AR, Fadae M, Bashizadeh Fakhar H (2016) Efficacy of ProTaper and Mtwo retreatment files in removal of gutta-percha and guttaflow from root canals. Iran Endod J 11: 184-187.

20. Das S, De Ida A, Das S, Nair V, Saha N, et al. (2017) Comparative evaluation of three different rotary instrumentation systems for removal of gutta-percha from root canal during endodontic retreatment: $A n$ in vitro study. J Conserv Dent 20: 311-316.

21. Marques da Silva B, Baratto-Filho F, Leonardi DP, Henrique Borges A, Volpato L, et al. (2012) Effectiveness of ProTaper, D-RaCe, and Mtwo retreatment files with and without supplementary instruments in the removal of root canal filling material. Int Endodontic J 45: 927-932.

22. de Souza PF, Oliveira Goncalves LC, Franco Marques AA, Sponchiado Junior EC, Roberti Garcia Lda F, et al. (2015) Root canal retreatment using reciprocating and continuous rotary nickel-titanium instruments. Eur J Dent 9: 234-239.

23. Schneider CA, Rasband WS, Eliceiri KW (2012) NIH Image to Image J: 25 years of image analysis. Nat Methods 9: 671-675.

24. Fatima K, Nair R, Khasnis S, Vallabhaneni S, Patil JD (2018) Efficacy of rotary and reciprocating single-file systems on different access outlines for gutta-percha removal in retreatment: An in vitro study. J Conserv Dent 21: 354-358. 